\title{
Non-Alcoholic Beverages from Fermented Cereals with Increased Oligosaccharide Content
}

\author{
Loreta Basinskiene ${ }^{1 *}$, Grazina Juodeikiene ${ }^{1}$, Daiva Vidmantiene ${ }^{1}$, Maija Tenkanen², \\ Tomas Makaravicius ${ }^{1}$ and Elena Bartkiene ${ }^{3}$ \\ ${ }^{1}$ Kaunas University of Technology, K. Donelaicio St. 73, LT-44029 Kaunas, Lithuania \\ ${ }^{2}$ University of Helsinki, Latokartanonkaari 11, FIN-00014 Helsinki, Finnland \\ ${ }^{3}$ Lithuanian University of Health Sciences, Veterinary Academy, Tilzes 18, LT- 47181 Kaunas, Lithuania
}

Received: February 3, 2015

Accepted: October 22, 2015

\begin{abstract}
Summary
The aim of this study is to develop a new technology for making traditional Lithuanian non-alcoholic beverage kvass from fermented cereals by extending the spectrum of raw materials (extruded rye) and applying new biotechnological resources (xylanolytic enzymes and lactic acid bacteria (LAB)) to improve its functional properties. Arabinoxylans in extruded rye were very efficiently hydrolysed into oligosaccharides by xylanolytic complex Ceremix Plus MG. Using Ceremix Plus MG and LAB fermentation, the yield of arabinoxylooligosaccharides and xylooligosaccharides in beverage was increased to 300 and $1100 \mathrm{mg} / \mathrm{L}$, respectively. Beverages fermented by LAB had lower $\mathrm{pH}$ values and ethanol volume fraction compared to the yeast-fermented beverage. The acceptability of the beverage fermented by Lactobacillus sakei was higher than of Pediococcus pentosaceus- or yeast-fermented beverages and similar to the acceptability of commercial kvass made from malt extract. The results showed that extruded rye, xylanolytic enzymes and LAB can be used for production of novel and safe high-value non-alcoholic beverages.
\end{abstract}

Key words: non-alcoholic beverage, extruded rye, lactic acid bacteria (LAB), xylanase, oligosaccharides

\section{Introduction}

Fermented foods and beverages are produced worldwide using various manufacturing techniques, raw materials and microorganisms (1). The problem is that production methods for most of traditional fermented foods are not optimised or industrialised, and are rather small-scale, localised processes. It is beneficial to revisit such traditional products and to conduct biotechnological investigations to explore and enhance their functional properties, and thus promote their commercial exploitation outside of their local market.
Kvass is a cereal-based beverage traditionally produced from fermented rye and barley malt, rye flour, and stale rye bread in Lithuania and other eastern European countries. It is a non-alcoholic beverage, so the ethanol content should be negligible, and it is considered to be spoiled if alcohol accumulates to higher levels. As opposed to sourdough bread, kvass undergoes no heat processing after fermentation and thus contains high cell counts of viable yeast and lactic acid bacteria (LAB). The microflora of kvass fermentation is normally composed of Saccharomyces cerevisiae and LAB, but the composition of species is expected to be quite variable due to differences

\footnotetext{
*Corresponding author: Phone: +370 37456 426; Fax: +370 37300 152; E-mail: loreta.basinskiene@ktu.lt 
in fermentation techniques and fermentation media. To date, microbial associations in kvass fermentation have been poorly investigated (2). Efforts to use pure starter cultures of $\mathrm{LAB}$ to produce acceptable kvass have not been documented.

LAB play a key role in food fermentations where they not only contribute to the development of the desired sensory properties in the final product but also to their microbiological safety (3). The antimicrobial effect of LAB is mainly related to the production of organic acids; however, some strains are able to synthesise antimicrobial substances - bacteriocins (3). During recent years the interest in bacteriocin-producing $\mathrm{LAB}$ has increased because of their potential to produce natural antimicrobial agents to enhance the safety of food products. The application of such LAB for non-alcoholic cereal-based beverage production provides new opportunities for development of functional fermented products.

Cereals are important source of hemicelluloses, which include arabinoxylans, $\beta$-glucans and arabinogalactans, also called dietary fibre (4). Among commonly grown cereals, rye is considered to be a healthy cereal with its high content of dietary fibre and associated components. The growing interest in foods and beverages with increased dietary fibre content is observed worldwide. Such foods and beverages are often called prebiotic foods, because of their ability to stimulate the growth of beneficial colonic microflora $(5,6)$. Research on prebiotics and other novel health-promoting food components has been intensive for over a decade. Arabinoxylan-derived arabinoxylooligosaccharides (AXOS), which may have various chemical structures, depending on the xylan source and the degradation method used, stand increasingly in the spotlight as potential prebiotics $(7,8)$. During the past decade, the studies of the possibilities to produce the AXOS by using biocatalytic conversion have received more attention. The enzymatic hydrolysis allows control of the end-products and to obtain AXOS having the desired degree of polymerization and substitutions (9). Therefore, there is an interest in new enzymatic technologies for partial and selective degradation of arabinoxylan (AX).

Most recently, extrusion technology has been used in the development of novel, value-added foods $(10,11)$. Extrusion cooking is preferable to other food-processing techniques because it is a continuous process with high productivity and significant nutrient retention, owing to the high temperature and short time required. During extrusion cooking, the raw materials undergo many chemical and structural transformations, such as starch gelatinization, protein denaturation, complex formation between amylose and lipids (12). No significant changes were found in dietary fibre content at mild or moderate extrusion conditions, but some fibre components could be solubilised (13). In addition, the extrusion denatures undesirable enzymes, inactivates some antinutritional factors, destructs naturally present toxins, and sterilises the final product (14). The application of new raw materials in the extrusion process opens perspectives both for the increase of the assortment of extruded products and the development of novel components for food industry that exhibit specific technological properties.
The aim of this study is to develop a new technology for making traditional Lithuanian non-alcoholic beverage kvass from fermented cereals by extending the spectrum of raw materials such as extruded rye and applying new biotechnological resources such as xylanolytic enzymes and antimicrobially active $\mathrm{LAB}$ to improve the functional properties.

\section{Materials and Methods}

\section{Raw materials and enzymes}

Rye wholemeal extruded by a single-screw extruder was supplied by the miller Ustukiu Malunas (Pasvalys, Lithuania). Extrusion conditions were: feed rate $110 \mathrm{~kg} / \mathrm{h}$, temperature $45 / 65 / 110{ }^{\circ} \mathrm{C}$ (individual zones), screw speed $350-410 \mathrm{rpm}$. The extruded rye flour was passed through a 0.5 -mm sieve.

Four commercial xylanolytic enzyme preparations were used for degradation of AX to AXOS and XOS: Ceremix Plus MG derived from Humicola insolens and Bacillus licheniformis, Pentopan Mono BG from Thermomyces lanuginosus (both from Novozymes A/S, Bagsværd, Denmark), Depol 680P from Bacillus spp. and Aspergillus spp. and Depol 692L from Trichoderma reesei and Aspergillus spp. (both from Biocatalysts Ltd., Parc Nantgarw, Wales, UK). Additionally, Bakezyme P500, an $\alpha$-amylase preparation from Aspergillus oryzae (DSM, Heerlen, The Netherlands) and AMG 300L, an amyloglucosidase preparation from Aspergillus niger (Novozymes A/S) were used for rye mash liquefaction.

Activity profiles of the enzyme preparations used in the study were determined before the experiment. $\beta$-Xylanase activity was measured using the method of Bailey et al. (15) with $1 \%$ birchwood xylan (Sigma-Aldrich, Steinheim, Germany) as a substrate. $\beta$-Glucanase activity was measured with medium viscosity barley $\beta$-glucan $1 \%$ (Megazyme International Ireland, Bray, Ireland) as a substrate according to Zurbriggen et al. (16). The $\alpha$-arabinosidase, $\beta$-xylosidase and $\beta$-glucosidase activities were measured according to Poutanen et al. (17) and Poutanen and Puls (18) using $2 \mathrm{mM} p$-nitrophenyl- $\alpha$ -L-arabinofuranoside, $5 \mathrm{mM} p$-nitrophenyl- $\beta$-D-xylopyranoside and $1 \mathrm{mM} p$-nitrophenyl- $\beta$-D-glucopyranoside (Sigma-Aldrich) substrates, respectively. High $\beta$-xylanase activity with only low side activities of $\beta$-glucanase and $\beta$-glucosidase was found in Pentopan Mono BG. Ceremix Plus MG, Depol 680P and Depol 692L preparations contained high $\beta$-glucanase activity with side activities of $\beta$-xylanase, $\beta$-xylosidase (except Depol 692L), $\alpha$-arabinosidase and $\beta$-glucosidase.

\section{Lactic acid bacteria and yeast}

Lactobacillus sakei KTU05-6 (optimal temperature 30 ${ }^{\circ} \mathrm{C}$ ) and Pediococcus pentosaceus KTU05-10 (optimal temperature $37^{\circ} \mathrm{C}$ ) from culture collection of the Department of Food Science and Technology (Kaunas University of Technology, Kaunas, Lithuania) were used for beverage fermentation. Tested LAB were isolated from spontaneous rye sourdough and selected due to their high antimicrobial activity (19). LAB were cultured in MRS broth 
(CM0359; Oxoid Ltd, Hampshire, UK) at appropriate temperatures for $48 \mathrm{~h}$ prior to use. For parallel studies dry baker's yeast Saccharomyces cerevisiae (Fermentis, Marcqen-Baroeul, France) was used.

\section{Arabinoxylan enzymatic hydrolysis}

For hydrolysis of $\mathrm{AX}, 2.5 \mathrm{mg}$ of each rye sample were suspended in $1 \mathrm{~mL}$ of $0.1 \mathrm{M}$ sodium acetate buffer $(\mathrm{pH}=5)$ and incubated with four different enzyme preparations separately (600 xylanase units (XU) per g of cereals) at $55^{\circ} \mathrm{C}$ for $5 \mathrm{~h}$. Enzymatic reaction was stopped by heating the reaction mixture at $100{ }^{\circ} \mathrm{C}$ for $10 \mathrm{~min}$. The degree of $\mathrm{AX}$ degradation was determined by high-performance anion-exchange chromatography (HPAEC).

\section{Preparation of beverages}

Modified technological scheme for traditional kvass production was used to prepare a non-alcoholic beverage from extruded rye under laboratory conditions. The beverage mash was prepared from extruded wholemeal rye and tap water $\left(55^{\circ} \mathrm{C}\right)$ at a ratio of $1: 50$ and treated by enzymatic hydrolysis. Simultaneous enzymatic liquefaction and saccharification step was performed in $2 \mathrm{~h}$ at $55^{\circ} \mathrm{C}$ by adding selected amounts of $\alpha$-amylase (48.6 amylase units (AU) per g of cereals) and amyloglucosidase (20 glucosidase units (GU) per g); additionally $\beta$-xylanolytic enzyme preparation Ceremix Plus MG (12.5 XU/g) was added for the degradation of non-starch polysaccharides. The activities of enzymes were selected according to the producer's recommendations and the results of initial tests. After liquefaction, the mash was boiled at $100{ }^{\circ} \mathrm{C}$ for $10 \mathrm{~min}$ to inactivate the enzymes, and cooled down to a temperature suitable for $\mathrm{LAB}\left(30\right.$ and $\left.37^{\circ} \mathrm{C}\right)$ or yeast $\left(30^{\circ} \mathrm{C}\right)$. The mash was inoculated with $10 \%$ of starter culture suspension $\left(10^{8}\right.$ colony-forming units ( $\left.\mathrm{CFU}\right)$ per $\mathrm{g}$, moisture content $65 \%$ ) or dry yeast ( $0.6 \mathrm{~g}$ per $\mathrm{L}$ of mash). Fermentation was carried out for 48-60 h and samples for oligo- and monosaccharide analysis were collected every $12 \mathrm{~h}$ and filtered with Eppendorf filtration system (Eppendorf, Hamburg, Germany). Sweetness of fermented mash was adjusted by adding sugar, and caramelised malt was used to obtain brown colour of the drink. The beverage was then cooled, filtered and samples were taken for quality evaluation. The rest of the beverage was dispensed into $250-\mathrm{mL}$ amber glass bottles. The bottles were closed with screw caps and stored at $0-6{ }^{\circ} \mathrm{C}$ for 30 days for microbial analysis. Kvass produced from commercial rye malt extract and fermented by yeast under the same conditions served as the control. All fermentations were performed in duplicates.

\section{Chromatographic analysis of saccharides}

HPAEC analysis of oligosaccharides extracted from extruded rye was performed on HPLC system, equipped with Waters 717 Plus autosampler, two Waters 515 HPLC pumps (Waters, Milford, MA, USA), analytical column CarboPac PA-100 $(250 \mathrm{~mm} \times 4 \mathrm{~mm})$ and guard column CarboPac PA-100 Guard ( $50 \mathrm{~mm} \times 4 \mathrm{~mm}$; Dionex, Sunnyvale, CA, USA). Decade pulsed amperometric detector (PAD) (Waters) with a gold electrode (Antec Leyden, Zoeterwoude, The Netherlands) was used in pulse mode at $30^{\circ} \mathrm{C}$ and Millenium 32 software (Waters) for instrument control and data handling.
The HPAEC-PAD system for determination of monosaccharides was equipped with Waters 2707 autosampler, three Waters 515 HPLC pumps, analytical column CarboPac PA-1 (250 mm $\times 4 \mathrm{~mm})$ and guard column CarboPac PA-1 Guard (50 mm×4 mm; Dionex), Waters 2465 pulse amperometric detector (PAD) and Empower 2 software (Waters). The mobile phases were filtered through 0.45$-\mu \mathrm{m}$ GH Polypro membrane filters (Pall Corporation, Port Washington, NY, USA) and degassed using helium.

The eluents for gradient analysis of the oligosaccharides were $\mathrm{A}: 1 \mathrm{M}$ sodium acetate in $100 \mathrm{mM}$ sodium hydroxide (Sigma-Aldrich) and B: $100 \mathrm{mM}$ sodium hydroxide. The first isocratic phase was $15 \mathrm{~min}$ in $100 \% \mathrm{~B}$, followed by a linear gradient from $100 \%$ B to $88 \%$ B and $12 \% \mathrm{~A}$ in $20 \mathrm{~min}$. The second isocratic phase was $5 \mathrm{~min}$ in $88 \% \mathrm{~B}$ and $12 \% \mathrm{~A}$. The second linear gradient was back to $100 \% \mathrm{~B}$ in $5 \mathrm{~min}$. The last isocratic phase was $5 \mathrm{~min}$ in $100 \% \mathrm{~B}$, in which the column was stabilised before the next injection. The total analysis time was $50 \mathrm{~min}$ and the flow rate was $1 \mathrm{~mL} / \mathrm{min}$.

The eluents for gradient analysis of the monosaccharides were $A$ : $200 \mathrm{mM}$ sodium hydroxide and $\mathrm{B}$ : water. The first isocratic phase was $13 \mathrm{~min}$ in $18 \% \mathrm{~A}$ and $82 \% \mathrm{~B}$, followed by a linear gradient to $100 \% \mathrm{~A}$ in $9 \mathrm{~min}$. The second isocratic phase was $15 \mathrm{~min}$ in $100 \% \mathrm{~A}$. The second linear gradient was back to $18 \% \mathrm{~A}$ and $82 \% \mathrm{~B}$ in $8 \mathrm{~min}$. The last isocratic phase was $10 \mathrm{~min}$ in $18 \% \mathrm{~A}$ and $82 \% \mathrm{~B}$. The total analysis time was $55 \mathrm{~min}$ and the flow rate was 1 $\mathrm{mL} / \mathrm{min}$.

External standards were used in both oligo- and monosaccharide analysis for accurate identification and quantification of the formed sugars. For oligosaccharide analysis, the mixtures of XOS (from $\mathrm{X}_{2}$ to $\mathrm{X}_{6}$ ) and maltooligosaccharides (from $M_{3}$ to $M_{7}$ ) (Megazyme International Ireland) were used. AXOS $\left(\mathrm{A}^{3} \mathrm{X}, \mathrm{A}^{2} \mathrm{X}, \mathrm{A}^{2} \mathrm{XX}, \mathrm{A}^{2,3} \mathrm{X}, \mathrm{A}^{2,3} \mathrm{XX}\right)$ were prepared at the University of Helsinki, Finland. The preparation, purification and identification of these AXOS are described by Rantanen et al. (20) and Pastell et al. (21). The amount of isolated AXOS was analysed in those papers and these values were used as standard to quantify unknown AXOS mixtures. Additionally, maltose, cellobiose, 1,3-1,4- $\beta$-glucotriose, two glucotetroses (different in structure) and galactotetrose were used (Megazyme International Ireland). The peak heights $(\mathrm{mV})$ were used in the quantification of carbohydrates. For the monosaccharides, an external standard mixture containing arabinose, glucose, fructose, xylose (Merck KGaA, Darmstadt, Germany) and sucrose (Sigma-Aldrich) was used. The external standard mixture was injected after every four samples in both methods to monitor the retention times and detection responses.

\section{Beverage quality evaluation}

Total titratable acidity (TTA) was analysed by titration with $0.1 \mathrm{M} \mathrm{NaOH}$ solution, using phenolphtalein as indicator, and expressed in degrees. One degree $\left(1^{\circ}\right)$ of acidity corresponds to $1 \mathrm{~mL}$ of $1 \mathrm{M} \mathrm{NaOH}$ required to neutralise the organic acids present in $100 \mathrm{~mL}$ of sample. The $\mathrm{pH}$ value was measured and recorded using a $\mathrm{pH}$ electrode (PP-15; Sartorius, Goettingen, Germany). Volatile acid content was determined by steam distillation and after titration with 0.1 
$\mathrm{M} \mathrm{NaOH}$ it was expressed in $\mathrm{g}$ of acetic acid per L. Concentration of lactic acid $(\mathrm{g} / \mathrm{L})$ was calculated from the differences between TTA and volatile acidity.

Contents of ethanol (\% by volume) and extractable materials (\% by mass) were determined after distillation by densitometric method using pycnometer at $20^{\circ} \mathrm{C}$. Byproducts of fermentation potentially considered as flavour compounds or as impurities (methanol, higher alcohols and esters) were analysed using a Hewlett-Packard 5890 gas chromatograph (Hewlett-Packard, Wilmington, DE, USA) equipped with a split-splitless injector and a flame ionisation detector (FID). The injection temperature was $200{ }^{\circ} \mathrm{C}$ and helium served as a carrier gas with a flow rate of $1.2 \mathrm{~mL} / \mathrm{min}$. Compounds were separated on a column Zebron ZB-WAX (30 m×0.25 mm×0.25 $\mu \mathrm{m}, 100 \%$ polyethylene glycol; Phenomenex, Torrance, CA, USA). The temperature program used was: initial temperature of $40{ }^{\circ} \mathrm{C}$ for $5 \mathrm{~min}$, rising to $100{ }^{\circ} \mathrm{C}$ at a rate of $4{ }^{\circ} \mathrm{C} / \mathrm{min}$, and a $2 \mathrm{~min}$ hold. The detection temperature was set at $250{ }^{\circ} \mathrm{C}$. Qualitative analysis was done by comparison of retention times of the chromatogram of the kvass samples to that of the standard solution of 6 alcohols and esters (methyl acetate, ethyl acetate, methanol, propanol, isobutanol, isoamyl alcohol; Sigma-Aldrich). A standard solution was prepared by dissolving the analysed compounds in $96 \%$ ethanol. Quantitative analysis was conducted using generated calibration curves.

\section{Microbial analysis of beverages}

The effect of LAB on the microbiological characteristics of beverages was determined by counting their number and the total number of microorganisms after 1, 10, 20 and 30 days of storage. LAB counts were determined on MRS agar (Liofilchem, Roseto degli Abruzzi, Teramo, Italy) using plate count techniques. Plates were incubated for $(72 \pm 4) \mathrm{h}$ under anaerobic conditions (using atmosphere generation system AnaeroGen; Oxoid, Basingstoke, UK). The experiment was carried out in triplicate. Microbiological contamination of fermented products was evaluated by calculating the total number of microorganisms and was expressed in CFU/mL using plate count agar (Liofilchem) according to ISO 4833-2:2013 method (22).

\section{Sensory evaluations of the beverages}

Sensory evaluations were conducted by 11 panellists, consisting of KTU staff and students, using a 7-point rating scale for the colour, odour and flavour attributes. Value of 1 corresponded to the lowest intensity and of 7 to the highest intensity of the attribute. Overall acceptability was evaluated using a 9-point hedonic scale where 9 is 'like extremely' and 1 'dislike extremely'. Coded samples were served and water was provided for rinsing between the sensory evaluations of the samples.

\section{Statistical analysis}

All analytical determinations were performed at least in triplicates. Results were expressed as mean value \pm standard deviation (S.D.). Statistical data analysis was conducted using a Microsoft Excel spreadsheet, and the statistical program for Windows (SPSS, v. 16.0; IBM Corporation, Armonk, NY, USA) was used for comparison of the mean values by one-way analysis of variance. The results were significant at $\mathrm{p}<0.05$

\section{Results and Discussion}

\section{Effect of enzyme preparations on rye arabinoxylan hydrolysis}

All tested enzyme complexes were capable of degrading rye $\mathrm{AX}$ main chain, releasing various monosaccharides and AXOS. D-Arabinose (Ara), D-xylose (Xyl) and D-glucose (Glc) were determined as a result of full AX and starch degradation (Fig. 1a). The results showed that Depol 680P and Depol 692L gave the highest yields of Glc (602.0 and $382.2 \mathrm{mg} / \mathrm{g}$, respectively) and Xyl (23.2 and $23.4 \mathrm{mg} / \mathrm{g}$ ). Thermomyces lanuginosus-derived xylanase Pentopan Mono BG had the highest activity, but unexpectedly poor release of $\mathrm{Xyl}$, which can be explained by this xylanase assignation to family GH11. According to the results of other authors, a GH11 family xylanase needs the presence of other xylanolytic enzymes to act effectively on AX for complete degradation of polymeric chain $(23,24)$. Kormelink et al. (25) reported that pure GH10 family endo-1,4- $\beta$-D-xylanases (from Aspergillus awamori) converted up to $72 \%$ of the wheat flour AX into mono-, di- and oligosaccharides with the degree of polimerisation (DP) of 3-10, whereas endo-1,4- $\beta$-D-xylanases from GH11 family hydrolysed only $50 \%$ of AX into oligosaccharides with $\mathrm{DP}=5-10$. Shorter AXOS were also formed by GH10 family endo-1,4- $\beta$-D-xylanases, compared to those produced by GH11 family endo-1,4- $\beta$-D-xylanases $(7,26)$.

Analysis showed that most of the tested enzyme preparations formed the following AXOS: singly substituted (position $C 2)$ arabinoxylotriose $\left(A^{2} X X\right)$, singly substituted (position $C 3$ ) arabinoxylobiose $\left(A^{3} X\right)$ and doubly substituted (positions $C 2$ and $C 3$ ) arabinoxylotriose $\left(A^{2,3} \mathrm{XX}\right)$. Highest yield of $A^{2} X X(5.5 \mathrm{mg} / \mathrm{g}), \mathrm{A}^{2,3} \mathrm{X}(7.5 \mathrm{mg} / \mathrm{g}), \mathrm{A}^{2,3} \mathrm{XX}$ $(2.6 \mathrm{mg} / \mathrm{g})$ and $\mathrm{A}^{3} \mathrm{X}(3.8 \mathrm{mg} / \mathrm{g})$ was determined in extruded rye samples treated with Ceremix (Fig. 1b). Depol 692L released $A^{2} X X(5.5 \mathrm{mg} / \mathrm{g})$ and $A^{2,3} X X(1.6 \mathrm{mg} / \mathrm{g})$. Other enzyme complexes were not effective in releasing these AXOS. Therefore, H. insolens- and B. licheniformis-derived enzyme preparation Ceremix was chosen for production of higher value non-alcoholic cereal-based beverage.

Higher value of cereal-based products is related to XOS and AXOS, which according to other authors have shown promising prebiotic properties $(27,28)$. However, linear oligosaccharides may be fermented rapidly in the colon and thus those with more complex carbohydrate structures are currently studied to find more slowly fermenting prebiotics $(29,30)$. Van Crayeveld et al. (31) determined that AXOS with DP $\leq 3$ caused increased colonic acetate and butyric concentrations and increased the amount of bifidobacteria. However, little information is available on which AXOS would be the most beneficial, because it is complicated to obtain enough purified and well-defined AXOS preparations.

\section{Saccharide profiles in fermented rye mash}

Lactic acid bacteria P. pentosaceus and L. sakei and baker's yeast were used for preparation of a non-alcoholic 

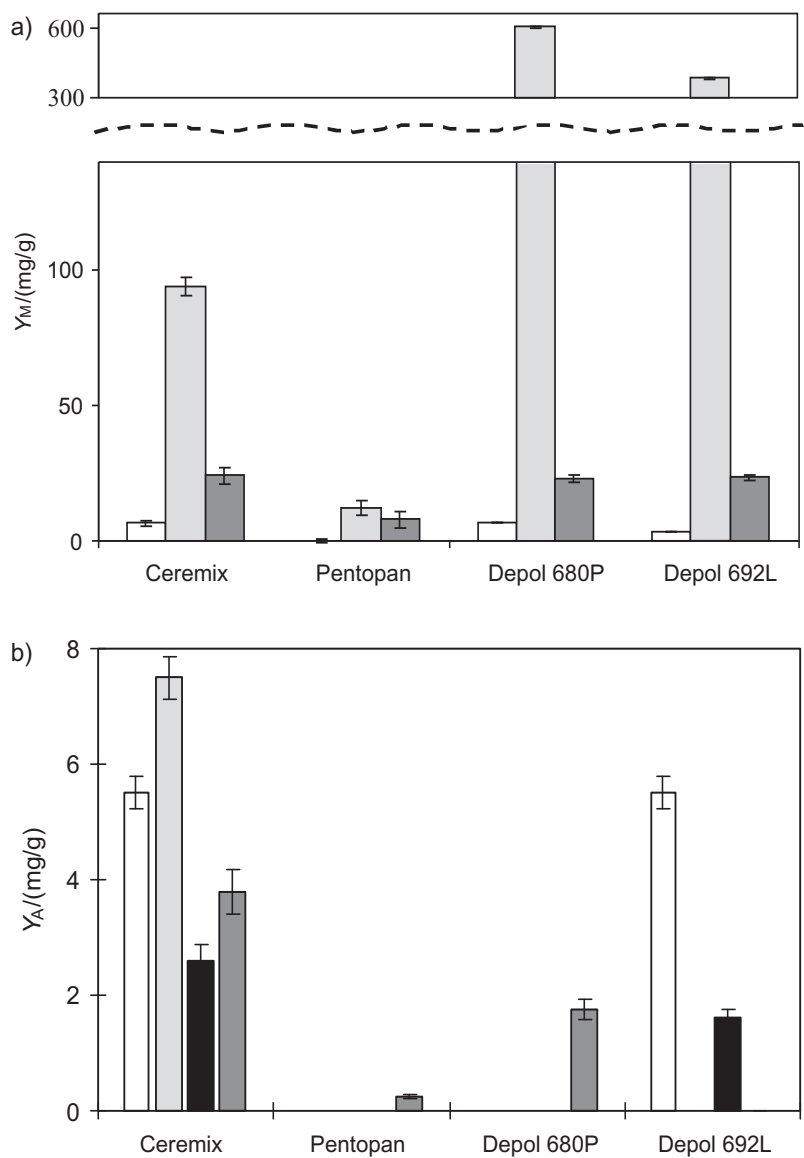

Fig. 1. Yields of: a) monosaccharides $\left(Y_{M}\right)$ ( $\square$ arabinose, $\square$ glucose and $\mathrm{xylose})$, and $\mathrm{b}$ ) arabinoxylooligosaccharides $\left(Y_{\mathrm{A}}\right)$ $\left(\square A^{2} X X, \square A^{2,3} X, \square A^{2,3} X X \square A^{3} X\right)$ in enzymatically treated extruded rye beverage from extruded rye. Different enzymatic treatments were tested for extruded rye mash preparation: $(i)$ with enzyme composition of $\alpha$-amylase from $A$. oryzae, glucoamylase from $A$. niger and xylanolytic enzyme complex from $H$. insolens and $B$. licheniformis (as the best rye AX-degrading enzyme preparation), and (ii) only with xylanolytic enzyme complex. Control mash was prepared from non-enzymatically treated extruded rye. Efficiency of fermentation process was evaluated based on the changes in $\mathrm{pH}$ and TTA, saccharide mass fraction as well as the amount of ethanol and some volatile compounds.

Changes in saccharide mass fraction during fermentation were analysed by HPAEC every $12 \mathrm{~h}$ (Fig. 2). The consumption rate of Glc and sucrose (Suc) after $24 \mathrm{~h}$ of fermentation showed that the LAB used Glc first as the main substrate, and only when the mass fraction of this monosaccharide in fermentation medium was low, Suc was used (Table 1). In non-enzymatically treated mash, the LAB decreased the mass fraction of Glc by $62.1 \%(P$. pentosaceus) and $69.0 \%$ (L. sakei); additionally, Suc mass fraction was decreased by 62.3 and $61.1 \%$, respectively. After treatment with xylanolytic enzyme complex, P. pentosaceus and L. sakei consumed 88.5 and $75.7 \%$ of Glc, respectively, and Suc mass fraction remained intact. In the samples treated with amylolytic and xylanolytic enzyme complexes, Glc mass fraction decreased only by $19.3 \%$ ( $P$. pentosaceus) and $5.2 \%$ (L. sakei), the amount of Suc was not changed. The mass fractions of Ara (10.9-15.2 mg/g) and $\mathrm{Xyl}(8.1-13.7 \mathrm{mg} / \mathrm{g})$ were almost similar in all enzymatically treated samples fermented with L. sakei and $P$. pentosaceus and remained unchanged until the end of fermentation.

No significant changes ( $p>0.05)$ of XOS and AXOS in enzymatically treated rye mash were detected during fermentation (Table 1). The following XOS were identified:

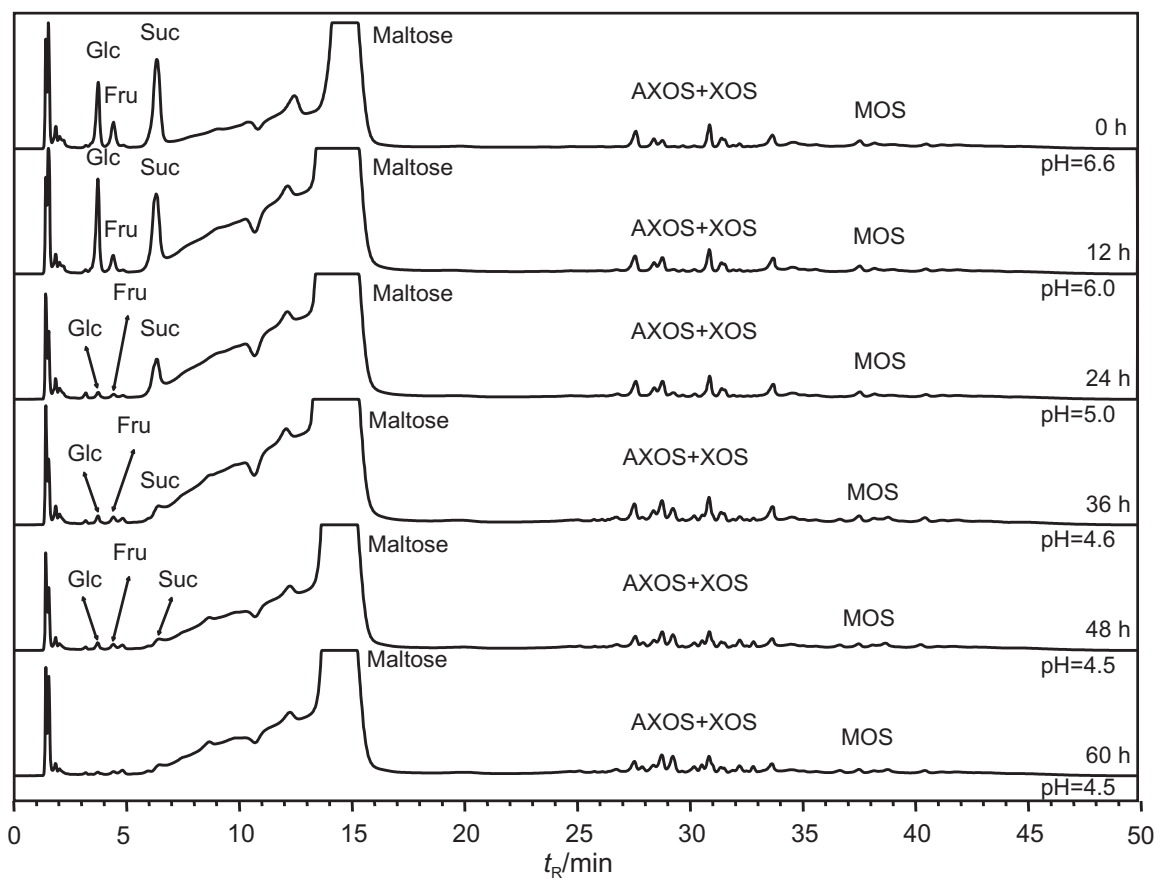

Fig. 2. HPAEC elution profiles of the mono- and oligosaccharides, obtained after fermentation of extruded rye by Pediococcus pentosaceus KTU05-10. Glc=glucose, Fru=fructose, Suc=sucrose, AXOS=arabinoxylooligosaccharides, XOS=xylooligosaccharides, MOS=maltooligosaccharides, $t_{\mathrm{R}}=$ retention time 
Table 1. Mass fraction of saccharides determined in extruded rye mash during fermentation with Pediococcus pentosaceus and Lactobacillus sakei

\begin{tabular}{|c|c|c|c|c|c|c|c|}
\hline \multirow{2}{*}{$t($ fermentation $) / h$} & \multicolumn{4}{|c|}{$w($ mono-/disaccharides $) /(\mathrm{mg} / \mathrm{g})$} & \multicolumn{3}{|c|}{$w($ oligosaccharides $) /(\mathrm{mg} / \mathrm{g})$} \\
\hline & Xyl & Ara & Glc & Suc & XOS & AXOS & MOS \\
\hline \multicolumn{8}{|c|}{ P. pentosaceus } \\
\hline \multicolumn{8}{|c|}{ Amylolytic and xylanolytic enzyme complex } \\
\hline 0 & $8.2 \pm 0.3$ & $13.8 \pm 0.4$ & $238.6 \pm 7.3$ & $8.7 \pm 0.2$ & $52.7 \pm 1.6$ & $17.2 \pm 0.5$ & $364.7 \pm 9.1$ \\
\hline 24 & $8.3 \pm 0.3$ & $13.8 \pm 0.4$ & $186.4 \pm 5.8$ & $8.7 \pm 0.3$ & $53.5 \pm 1.6$ & $16.9 \pm 0.5$ & $349.7 \pm 9.0$ \\
\hline 48 & $8.1 \pm 0.2$ & $13.1 \pm 0.4$ & $150.4 \pm 4.7$ & $7.8 \pm 0.2$ & $51.9 \pm 1.6$ & $17.1 \pm 0.5$ & $345.8 \pm 9.1$ \\
\hline \multicolumn{8}{|c|}{ Xylanolytic enzyme complex } \\
\hline 0 & $12.0 \pm 0.4$ & $12.5 \pm 0.4$ & $128.6 \pm 3.9$ & $7.9 \pm 0.2$ & $53.6 \pm 1.6$ & $16.8 \pm 0.5$ & $362.2 \pm 9.2$ \\
\hline 24 & $9.4 \pm 0.3$ & $13.5 \pm 0.4$ & $14.8 \pm 0.4$ & $7.8 \pm 0.2$ & $53.7 \pm 1.6$ & $17.5 \pm 0.5$ & $365.6 \pm 9.3$ \\
\hline 48 & $9.4 \pm 0.3$ & $10.9 \pm 0.3$ & $4.0 \pm 0.1$ & $8.3 \pm 0.2$ & $52.4 \pm 1.6$ & $17.7 \pm 0.5$ & $378.7 \pm 8.9$ \\
\hline \multicolumn{8}{|l|}{ Without enzymes } \\
\hline 0 & n.d. & n.d. & $12.6 \pm 0.1$ & $8.1 \pm 0.3$ & $0.65 \pm 0.0$ & $2.3 \pm 0.0$ & $319.0 \pm 9.1$ \\
\hline 24 & n.d. & n.d. & $4.8 \pm 0.0$ & $3.4 \pm 0.2$ & $0.69 \pm 0.0$ & $2.9 \pm 0.0$ & $310.7 \pm 8.8$ \\
\hline 48 & n.d. & n.d. & $2.4 \pm 0.0$ & $1.5 \pm 0.2$ & $0.64 \pm 0.0$ & $3.1 \pm 0.0$ & $311.8 \pm 8.9$ \\
\hline \multicolumn{8}{|c|}{ L. sakei } \\
\hline \multicolumn{8}{|c|}{ Amylolytic and xylanolytic enzyme complex } \\
\hline 0 & $13.7 \pm 0.4$ & $11.5 \pm 0.3$ & $253.8 \pm 7.5$ & $7.3 \pm 0.3$ & $54.1 \pm 1.6$ & $18.0 \pm 0.5$ & $352.4 \pm 8.7$ \\
\hline 24 & $8.5 \pm 0.3$ & $14.4 \pm 0.4$ & $204.3 \pm 6.1$ & $7.3 \pm 0.3$ & $53.9 \pm 1.6$ & $17.6 \pm 0.6$ & $353.2 \pm 9.2$ \\
\hline 48 & $8.9 \pm 0.3$ & $15.2 \pm 0.5$ & $179.0 \pm 5.6$ & $7.1 \pm 0.3$ & $53.5 \pm 1.6$ & $17.3 \pm 0.6$ & $350.6 \pm 9.1$ \\
\hline \multicolumn{8}{|c|}{ Xylanolytic enzyme complex } \\
\hline 0 & $13.7 \pm 0.4$ & $13.4 \pm 0.4$ & $103.1 \pm 3.1$ & $6.4 \pm 0.2$ & $53.6 \pm 1.6$ & $16.6 \pm 0.5$ & $339.5 \pm 8.5$ \\
\hline 24 & $8.5 \pm 0.3$ & $14.6 \pm 0.4$ & $25.1 \pm 0.6$ & $6.5 \pm 0.2$ & $52.7 \pm 1.6$ & $15.9 \pm 0.5$ & $346.7 \pm 9.2$ \\
\hline 48 & $8.4 \pm 0.3$ & $14.9 \pm 0.5$ & $7.2 \pm 0.2$ & $4.3 \pm 0.2$ & $53.4 \pm 1.6$ & $16.5 \pm 0.5$ & $345.3 \pm 9.4$ \\
\hline \multicolumn{8}{|l|}{ Without enzymes } \\
\hline 0 & n.d. & n.d. & $12.9 \pm 0.1$ & $8.4 \pm 0.3$ & $1.3 \pm 0.0$ & $3.8 \pm 0.0$ & $312.9 \pm 8.3$ \\
\hline 24 & n.d. & n.d. & $4.0 \pm 0.0$ & $3.6 \pm 0.2$ & $1.2 \pm 0.0$ & $3.6 \pm 0.0$ & $306.2 \pm 8.8$ \\
\hline 48 & n.d. & n.d. & $2.0 \pm 0.0$ & $1.3 \pm 0.2$ & $1.2 \pm 0.0$ & $4.1 \pm 0.0$ & $299.8 \pm 8.7$ \\
\hline
\end{tabular}

$\mathrm{Xyl}=\mathrm{xylose}, \mathrm{Ara}=$ arabinose, $\mathrm{Glc}=$ glucose, Suc=sucrose, $\mathrm{XOS}=\mathrm{xylooligosaccharides}, \mathrm{XOS}=$ arabinoxylooligosaccharides, MOS=maltooligosaccharides, n.d.=not detected

xylobiose $\left(X_{2}\right)$, xylotriose $\left(X_{3}\right)$, xylopentose $\left(X_{5}\right)$ and xylohexose $\left(X_{6}\right)$, and their mass fractions were in the range of $6.5-6.8,2.3-2.5,29.9-31.5$ and $4.4-4.5 \mathrm{mg} / \mathrm{g}$, respectively (data not shown). The identified AXOS were determined in similar mass fractions (in $\mathrm{mg} / \mathrm{g}$ ): $\mathrm{A}^{2} \mathrm{XX} 2.6-2.8, \mathrm{~A}^{2,3} \mathrm{XX}$ 2.5-2.7, $\mathrm{A}^{2,3} \mathrm{X}$ 6.9-7.3, and $\mathrm{A}^{3} \mathrm{X}$ 4.5-4.8 (data not shown).

\section{Influence of microorganisms on beverage quality}

The changes in quality parameters ( $\mathrm{pH}$ and TTA) of beverages from enzymatically treated (with amylolytic and xylanolytic enzyme complex) extruded rye during fermentation by LAB or yeast are presented in Fig. 3. It was determined that $\mathrm{pH}$ of beverages fermented by LAB reached lower values (3.25-3.54) compared to yeast-fermented beverage (4.34). On the other hand, the TTA increased during fermentation, and higher amount of organic acids was detected in LAB-fermented beverages $\left(2.4-5.8^{\circ}\right)$ than in the yeast-fermented ones $\left(0.9^{\circ}\right)$. Among $\mathrm{LAB}, P$. pentosaceus produced twice more organic acids than L. sakei. According to the $\mathrm{pH}$ and TTA values, the in- crease of acidity was almost the same as after $24 \mathrm{~h}$. Small changes in $\mathrm{pH}$ and TTA values after $48 \mathrm{~h}$ of LAB fermentation as compared to $24 \mathrm{~h}$ showed that beverage fermentation using LAB can be completed within $24 \mathrm{~h}$.

Fermentation of traditional home-made kvass by yeast usually provides from 3 to $4 \%$ (by volume) of alcohol in the end product, but in non-alcoholic fermented beverage it should not exceed $1.2 \%$ (by volume). The replacement of yeast by LAB allowed decreasing alcohol content in the beverage to an appropriate amount and fulfilling this requirement for non-alcoholic beverages. Determination of alcohol content (Fig. 4a) showed that both LAB produced some amount of alcohol (0.1-0.3\%), but it did not exceed the limits for non-alcoholic beverages, while yeast produced $4.5 \%$ of alcohol.

LAB fermentation as compared to yeast provided more flavour compounds that participate in the formation of product aroma and taste (Fig. 4b). The main product of LAB fermentation is lactic acid, but some other compounds, like acetic acid, diacetyl, methylacetate or 

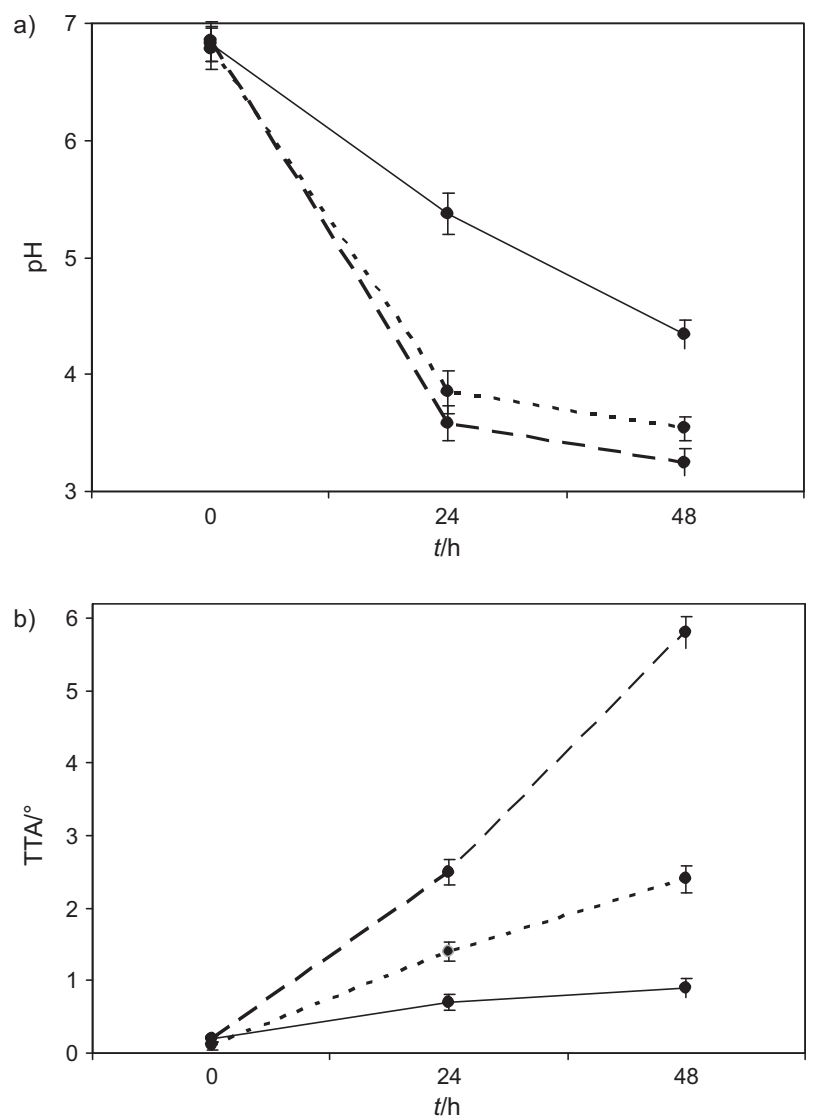

Fig. 3. Changes of: a) $\mathrm{pH}$ and b) titratable acidity (TTA) in beverages from enzymatically treated (with amylolytic and xylanolytic enzyme complex) extruded rye during fermentation with Pediococcus pentosaceus KTU05-10 (---•---), Lactobacillus sakei KTU05-6 (……) and Saccharomyces cerevisiae $(-\bullet-)$

various esters are released. Comparing both $\mathrm{LAB}$, it was determined that $P$. pentosaceus produced twice more acetic and lactic acids than L. sakei. Also in samples fermented by both LAB a small amount of methyl acetate was detected, which gives a pleasant aroma of fruits to beverages.

For estimation of LAB antimicrobial properties, lactic acid bacteria cell count and total microorganism cell count were evaluated during beverage storage for 30 days at $0-6{ }^{\circ} \mathrm{C}$ (Fig. 5). Analysis showed that after 30 days, viable cells of $L$. sakei decreased in the beverage more than 4 times (from $2.8 \cdot 10^{7}$ to $6.2 \cdot 10^{6} \mathrm{CFU} / \mathrm{mL}$ ), but viability of $\mathrm{LAB}$ remained high (more than $10^{6} \mathrm{CFU} / \mathrm{mL}$ ). The use of L. sakei resulted in a reduced total microorganism growth in the beverage during storage and confirmed that this $\mathrm{LAB}$ is capable of retarding the growth of extraneous microorganisms.

\section{Sensory characteristics and acceptability of beverages}

Statistically significant $(\mathrm{p} \leq 0.05)$ differences between commercial kvass made from rye malt extract (control) and beverages made from extruded rye fermented by yeast or LAB were determined in sweetness, sourness, colour and odour intensity (Fig. 6). The use of extruded rye for beverage production increased odour and decreased colour intensity of the product. Furthermore, using ex-
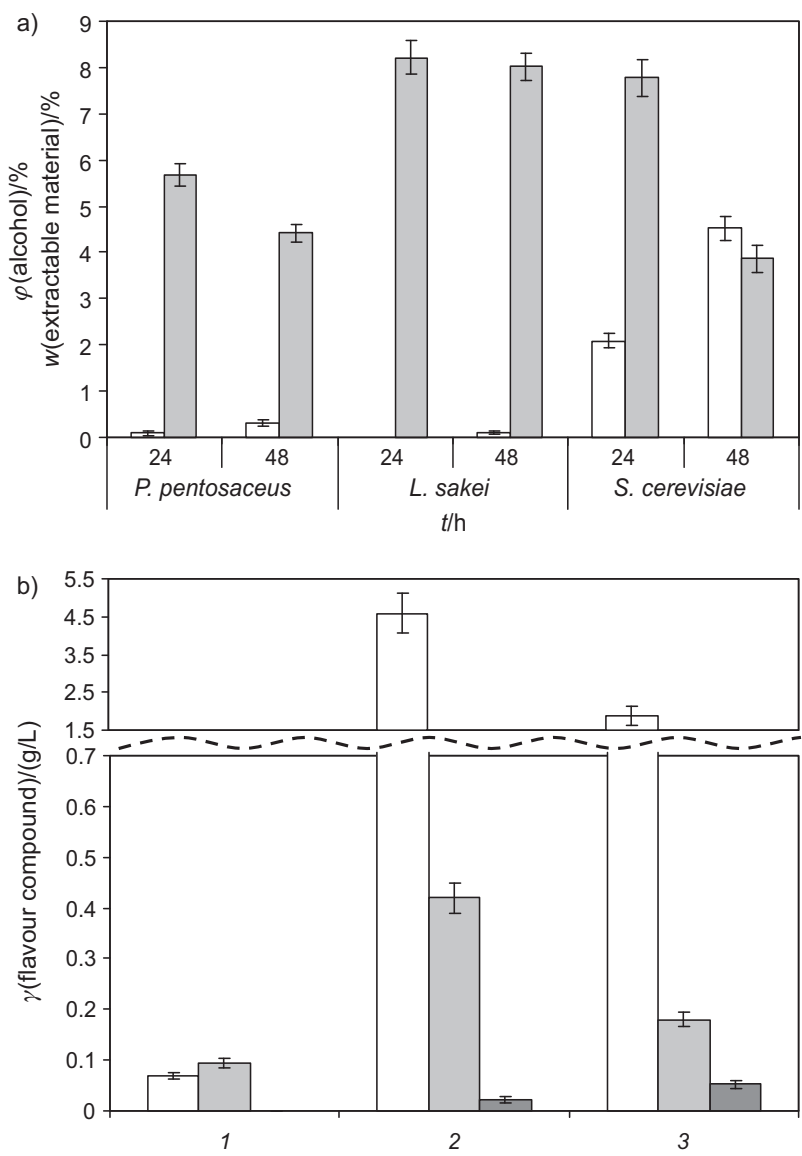

Fig. 4. Content of: a) $\square$ alcohol and $\square$ extractable materials, and b) flavour compounds ( $\square$ lactic acid, $\square$ acetic acid and $\square$ methyl acetate) in fermented beverage from enzymatically treated extruded rye

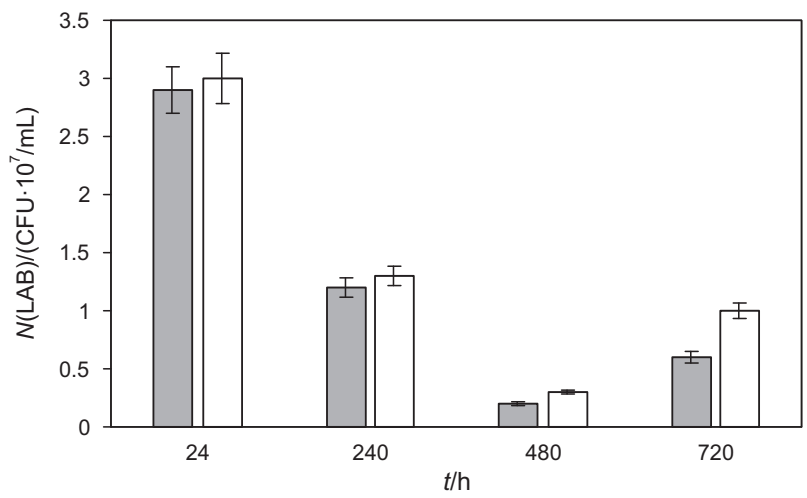

Fig. 5. The growth of microorganisms ( $\square$ total LAB cell count, $\square$ total microorganism cell count) during storage in a beverage fermented by Lactobacillus sakei

truded raw material for fermentation, intensity of brown colour was lost, compared to the control kvass. Beverages fermented by LAB also changed flavour properties: sweetness and bitterness decreased, while sourness increased.

Acceptability (Fig. 7) of beverages fermented by LAB was lower $(p \leq 0.05)$ compared to commercial kvass, but it was higher $(p \leq 0.05)$ than of beverage fermented by yeast. 


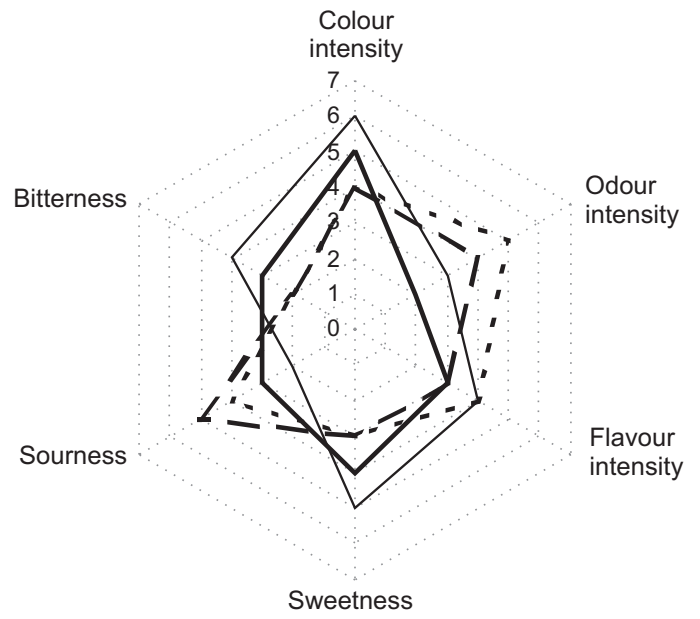

Fig. 6. Descriptive sensory analysis profile of commercial kvass (control) (-) and non-alcoholic beverages from extruded rye fermented by Saccharomyces cerevisiae (-), Pediococcus pentosaceus KTU05-10 (---) and Lactobacillus sakei KTU05-6 (-----)

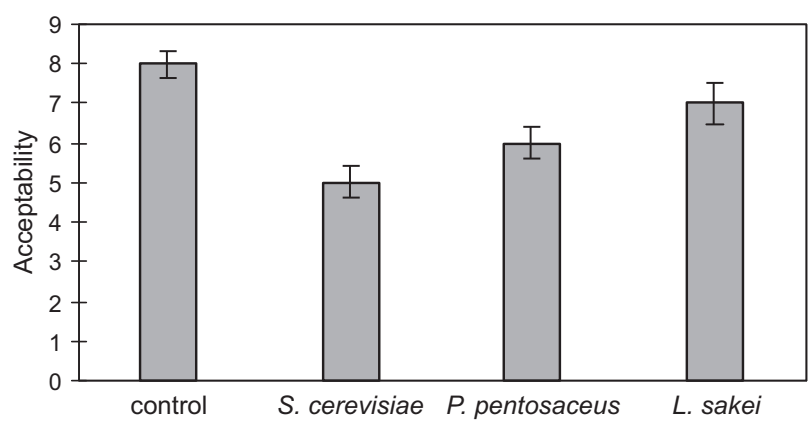

Fig. 7. Acceptability on a hedonic scale of commercial kvass (control) and non-alcoholic beverages from extruded rye fermented by Saccharomyces cerevisiae, Pediococcus pentosaceus KTU05-10 and Lactobacillus sakei KTU05-6

Comparing both LAB, higher acceptability was determined of the beverage fermented by L. sakei than by $P$. pentosaceus. Assessors preferred L. sakei-fermented beverage due to its higher flavour and odour intensity and lower sourness.

\section{Conclusions}

Extruded rye, xylanolytic enzymes and LAB can be used for production of novel, safe and higher value (with increased amount of oligosaccharides) non-alcoholic beverages. Using the selected xylanolytic enzyme complex Ceremix (Humicola insolens and Bacillus licheniformis) the yield of AXOS and XOS in beverage mash was increased by 300 and $1100 \mathrm{mg} / \mathrm{L}$, respectively, which remained intact during fermentation by LAB. Beverages fermented by the LAB (Pediococcus pentosaceus and Lactobacillus sakei) with antimicrobial activity had lower $\mathrm{pH}$ values (3.3-3.5) and higher TTA values $\left(2.4-5.8^{\circ}\right)$, higher concentrations of volatile compounds $(0.22-0.45 \mathrm{~g} / \mathrm{L})$ and less alcohol $(0.1-$ $0.3 \%$ by volume) than the beverage fermented by yeast $\left(\mathrm{pH}=4.3, \mathrm{TTA}=0.9^{\circ}, \gamma(\right.$ volatile compounds $)=0.09 \mathrm{~g} / \mathrm{L}$ and $\varphi($ alcohol $)=4.5 \%)$. The acceptability of the beverage from extruded rye fermented by L. sakei was higher than of the yeast-fermented beverages and close to the acceptability of commercial kvass made from rye malt extract.

\section{Acknowledgement}

The research was partly funded by a grant of the Research Council of Lithuania. The authors thank Novozymes A/S (Denmark), Biocatalyst Ltd. (UK) and DSM (the Netherlands) for providing the enzyme preparations.

\section{References}

1. Blandino A, AL-Aseeri ME, Pandiella SS, Cantero D, Webb C. Cereal-based fermented foods and beverages. Food Res Int. 2003;36:527-43.

http://dx.doi.org/10.1016/S0963-9969(03)00009-7

2. Dlusskaya E, Jänsch A, Schwab C, Gänzle MG. Microbial and chemical analysis of a kvass fermentation. Eur Food Res Technol. 2008;227:261-6. http://dx.doi.org/10.1007/s00217-007-0719-4

3. Dalié DKD, Deschamps AM, Richard-Forget F. Lactic acid bacteria - potential for control of mould growth and mycotoxins: a review. Food Control. 2010;21:370-80. http://dx.doi.org/10.1016/j.foodcont.2009.07.011

4. Saulnier L, Sado PE, Branlard G, Charmet G, Guillon F. Wheat arabinoxylans: exploiting variation in amount and composition to develop enhanced varieties. J Cereal Sci. 2007;46:261-81. http://dx.doi.org/10.1016/j.jcs.2007.06.014

5. Kamal-Eldin A, Lærke HN, Bach Knudsen KE, Lampi AM, Piironen V, Adlercreutz H, et al. Physical, microscopic and chemical characterisation of industrial rye and wheat brans from the Nordic countries. Food Nutr Res. 2009;53:10.3402/ fnr.v53i0.1912. http://dx.doi.org/10.3402/fnr.v53i0.1912

6. Gibson GR, Probert HM, Van Loo J, Rastall RA., Roberfroid MB. Dietary modulation of the human colonic microbiota: updating the concept of prebiotics. Nutr Res Rev. 2004;17: 259-75.

http://dx.doi.org/10.1079/NRR200479

7. Van Laere KMJ, Hartemink R, Bosveld M, Schols HA, Voragen AGJ. Fermentation of plant cell wall derived polysaccharides and their corresponding oligosaccharides by intestinal bacteria. J Agric Food Chem. 2000;48:1644-52.

http://dx.doi.org/10.1021/jf990519i

8. Grootaert C, Delcour JA, Courtin CM, Broekaert WF, Verstraete W, Van de Wiele T. Microbial metabolism and prebiotic potency of arabinoxylan oligosaccharides in the human intestine. Trend Food Sci Technol. 2007;18:64-71. http://dx.doi.org/10.1016/j.tifs.2006.08.004

9. Pastell H, Westermann P, Meyer AS, Tuomainen P, Tenkanen $M$. In vitro fermentation of arabinoxylan-derived carbohydrates by bifidobacteria and mixed fecal microbiota. J Agric Food Chem. 2009;57:8598-606. http://dx.doi.org/10.1021/jf901397b

10. Holguín-Acuña AL, Carvajal-Millán E, Santana-Rodríguez V, Rascón-Chu A, Márquez-Escalante JA, de León-Renova NEP, Gastelum-Franco G. Maize bran/oat flour extruded breakfast cereal: a novel source of complex polysaccharides and an antioxidant. Food Chem. 2008;111:654-7. http://dx.doi.org/10.1016/j.foodchem.2008.04.034

11. Patil RT, Berrios JDJ, Tang J, Swanson BG. Evaluation of methods for expansion properties of legume extrudates. Appl Eng Agric. 2007;23:777-83.

http://dx.doi.org/10.13031/2013.24044 
12. Singh S, Gamlath S, Wakeling L. Nutritional aspects of food extrusion: a review. Int J Food Sci Tech. 2007;42:916-29. http://dx.doi.org/10.1111/j.1365-2621.2006.01309.x

13. Kahlon TS, Edwards RH, Chow FI. Effect of extrusion on hypocholesterolemic properties of rice, oat, corn, and wheat bran diets in hamsters. Cereal Chem. 1998;75:897-903. http://dx.doi.org/10.1094/CCHEM.1998.75.6.897

14. Vasanthan T, Gaosong J, Yeung J, Li J. Dietary fiber profile of barley flour as affected by extrusion cooking. Food Chem. 2002;77:35-40. http://dx.doi.org/S0308-8146(01)00318-1

15. Bailey MJ, Biely P, Poutanen K. Interlaboratory testing of methods for assay of xylanase activity. J Biotechnol. 1992; 23:257-70. http://dx.doi.org/10.1016/0168-1656(92)90074-J

16. Zurbriggen B, Bailey MJ, Pentillä ME, Poutanen K, Linko M. Pilot scale production of heterologous Trichoderma reesei cellulose in Saccharomyces cerevisiae. J Biotechnol. 1990;13: 267-78. http://dx.doi.org/10.1016/0168-1656(90)90075-M

17. Poutanen K, Rättö M, Puls J, Viikari L. Evaluation of different microbial xylanolytic systems. J Biotechnol. 1987;6:4960. http://dx.doi.org/10.1016/0168-1656(87)90045-9

18. Poutanen K, Puls J. Characteristics of Trichoderma reesei $\beta$-xylosidase and its use in the hydrolysis of solubilized $x y-$ lans. Appl Microbiol Biotechnol. 1988;28:425-32. http://dx.doi.org/10.1007/BF00268208

19. Cizeikiene D, Juodeikiene G, Paskevicius A, Bartkiene E. Antimicrobial activity of lactic acid bacteria against pathogenic and spoilage microorganism isolated from food and their control in wheat bread. Food Control. 2013;31:539-45. http://dx.doi.org/10.1016/j.foodcont.2012.12.004

20. Rantanen H, Virkki L, Tuomainen P, Kabel M, Schols H, Tenkanen M. Preparation of arabinoxylobiose from rye xylan using family 10 Aspergillus aculeatus endo- $1,4-\beta$-D-xylanase. Carbohydr Polym. 2007;68:350-9. http://dx.doi.org/10.1016/j.carbpol.2006.11.022

21. Pastell H, Tuomainen P, Virkki L, Tenkanen M. Step-wise enzymatic preparation and structural characterization of singly and doubly substituted arabinoxylo-oligosaccharides with non-reducing end terminal branches. Carbohydr Res. 2008;343:3049-57. http://dx.doi.org/10.1016/j.carres.2008.09.013

22. ISO 4833-2:2013. Microbiology of the food chain - Horizontal method for the enumeration of microorganisms - Part 2: Colony count at 30 degrees $C$ by the surface plating tech- nique. Geneva, Switzerland: International Organization for Standardization (ISO); 2013.

23. Pell G, Taylor EJ, Gloster TM, Turkenburg JP, Fontes CMGA, Ferreira LMA, Nagy T, et al. The mechanisms by which family 10 glycoside hydrolases bind decorated substrates. J Biol Chem. 2004;27:9597-605. http://dx.doi.org/10.1074/jbc.M312278200

24. Vardakou M, Katapodis P, Samiotaki M, Kekos D, Panayotou G, Christakopoulos P. Mode of action of family 10 and 11 endoxylanases on water unextractable arabinoxylan. Int J Biolog Macromolec. 2003;33:129-34.

http://dx.doi.org/10.1016/S0141-8130(03)00077-1

25. Kormelink FJM, Gruppen H, Viëtor RJ, Voragen AGJ. Mode of action of the xylan-degrading enzymes from Aspergillus awamori on alkali-extractable cereal arabinoxylans. Carbohydr Res. 1993;249:355-67. http://dx.doi.org/10.1016/0008-6215(93)84100-K

26. Puchart V, Biely P. Simultaneous production of endo- $\beta-1,4-$ xylanase and branched xylooligosaccharides by Thermomyces lanuginosus. J Biotechnol. 2008;137:34-43. http://dx.doi.org/10.1016/j.jbiotec.2008.07.1789

27. Grootaert $C$, Van den Abbeele P, Marzorati M, Broekaert WF, Courtin CM, Delcour JA, et al. Comparison of prebiotic effects of arabinoxylan oligosaccharides and inulin in a simulator of the human intestinal microbial ecosystem. FEMS Microbiol Ecol. 2009;69:231-42. http://dx.doi.org/10.1111/j.1574-6941.2009.00712.x

28. Gullón P, González-Muñoz MJ, van Gool MP, Schols HA, Hirsch J, Ebringerová A, Parajó JC. Production, refining, structural characterization and fermentability of rice husk xylooligosaccharides. J Agric Food Chem. 2010;58:3632-41. http://dx.doi.org/10.1021/jf904508g

29. Kabel MA, Kórtenoeven L, Schols HA, Voragen AGJ. In vitro fermentability of differently substituted xylo-oligosaccharides. J Agric Food Chem. 2002;50:6205-10. http://dx.doi.org/10.1021/jf020220r

30. Moura P, Barata R, Carvalheiro F, Gírio F, Loureiro-Dias MC, Esteves MP. In vitro fermentation of xylo-oligosaccharides from corn cobs autohydrolysis by Bififdobacterrium and Lactobacillus strains. LWT - Food Sci Technol. 2007;40:96372 . http://dx.doi.org/10.1016/j.lwt.2006.07.013

31. Van Crayeveld V, Swennen K, Dornez E, Van de Wiele T, Marzorati M, Verstraete W, et al. Structurally different wheat-derived arabinoxylooligosaccharides have different prebiotic and fermentation properties in rats. J Nutr. 2008; 138:2348-55. http://dx.doi.org/10.3945/jn.108.094367 